Original article

\title{
Awareness of osteoporosis among female employees in Kerman, Iran
}

\author{
Mansoureh Safizadeh, Elahe Aminizadeh, Hossein Safizadeh
}

Kerman University of Medical Sciences, Kerman, Iran

Received 11 November 2014, Accepted 16 January 2015

(C) 2014, Safizadeh M., Aminizadeh E., Safizadeh H.

(C) 2014, Russian Open Medical Journal

Abstract: Background - Osteoporosis is a chronic multi-factorial disease characterized as low bone density and microarchitecture disturbance of bone tissue. Osteoporosis is known as a major health problem, but it can be prevented and treated in a great extent. Objective - The aim of the present study was to determine the rate of Iranian female employees' awareness of osteoporosis. Methods and Results - In a cross-sectional study, 400 female employees in Kerman were studied. Data were gathered using a researcher-made questionnaire. Mean awareness score of participants was $11.69 \pm 3.76$ that shows poor awareness. Participants with bachelor or higher degrees showed better awareness $(p<0.05)$. Conclusions - According to the obtained results, educational programs for increasing awareness of osteoporosis and its prevention are recommended.

Keywords: osteoporosis, awareness, employee

Cite as Safizadeh M, Aminizadeh E, Safizadeh H. Awareness of osteoporosis among female employees in Kerman, Iran. Russian Open Medical Journal 2015; 4 : e0103.

Correspondence to Hossein Safizadeh. Tel: +98-34-33224613. Mobile: +98-9133414414. Fax: +98-34-33224613. E-mail: hsafizade@kmu.ac.ir. Address: Afzalipour Medicine School, 22nd Bahman Blvd., Kerman, Iran, Postal Code: 7616914115.

\section{Introduction}

Osteoporosis is a common skeletal disease that is characterized by reduction of bone mass and loss of bone microarchitecture leading to increased risk of bone fractures $[1,2]$. These fractures might even occur during daily routine activities such as bending or raising [3]. Although, osteoporosis involves the whole skeleton, femur, vertebrae and distal radius are more prone to injury $[1,4]$.

Osteoporosis is a serious disabling disease affecting approximately $10 \%$ of the United States population [5]. It is more prevalent in women than men and Caucasian or Asian races, age increase, family history of osteoporosis, previous history of bone fractures, low body mass index, menopause under the age 45, calcium and vitamin $\mathrm{D}$ deficiencies, smoking, low physical activity and long-term treatment with corticosteroids are some of its risk factors $[6,7]$.

Since the occurrence and development of osteoporosis are mostly asymptomatic and it might not be diagnosed until the fracture occurrence, it is called a silent disease [3]. This disease causes increase of health care expenses, physical and psychological complications and decreased quality of life that all have negative effects on the affected individual, his/her family and the society. For this, it has been known as a major general health problem [7-9].

Although osteoporosis cannot be treated [10], it can be prevented in a great extent. The results of performed studies show the relationship between several health behaviors and decreased risk of osteoporosis [3]. Healthy life style, following good nutrition, doing exercise and preventing falls are among these behaviors [10]. It should be noted that prevention should be started at the time of bone formation and continued during adolescence and adult periods [11]. Studies have shown that planning for osteoporosis prevention requires sufficient information about people health knowledge and beliefs [12]. Meanwhile, awareness of osteoporosis symptoms helps early diagnosis of the disease, encourages help-seeking behaviors and decreases disease complications [3].

It seems that on-time prevention of osteoporosis and also early diagnosis and adequate treatment require sufficient awareness of the disease and its prevention in the community, especially among women; therefore, the present study was designed and performed with the aim of determining the awareness of Kerman female employees in relation to osteoporosis.

\section{Material and Methods}

In this cross-sectional study, the awareness of female official employees of Kerman, the center of largest province of Iran, toward osteoporosis was studied. The study had been approved by thesis committee of Afzalipour School of Medicine, Kerman University of Medical Sciences and all ethical points were considered; that is, first the aim of study was explained for each participant and after obtaining oral consent, the participant was entered into the study. All participants were ensured of the 
confidentiality of their information. From all female employees working in different offices of Kerman city, 400 ones were selected through convenience sampling and entered into the study. Data were gathered through a researcher-made questionnaire consisting of two sections. The first section was related to the demographic features and the second to the questions about awareness toward osteoporosis extracted from the questionnaire used by Jalili et al [12] with some modifications. It had 22 questions related to risk factors and symptoms of osteoporosis and its prevention. In order to calculate the awareness score, each correct answer was given 1 and "I do not know" and incorrect answers were given 0 (score domain=0-22). The questionnaire validity was approved by evaluating content validity and reliability was approved by calculating Cronbach's Alpha $(\alpha=0.79)$. Data analysis was done using t-test and ANOVA, and through SPSS17 software with considering $p<0.05$ as statistically significant.

\section{Results}

A total of 400 female employees of Kerman were participated in the present study. After omitting two incomplete questionnaires, 398 questionnaires were analyzed. Mean $( \pm S D)$ age of participants was $35.5( \pm 8.27)$ years (age range $=20-60$ years). Most participants were married (77.8\%) of whom, $79 \%$ had one or two children and 45 ones (11.4\%) were in menopause statues. From all, only 3 ones $(0.8 \%)$ were cigarette smoker. Almost all participants (96.7\%) had some information about osteoporosis (Table 1). The most frequent source of information about osteoporosis was radio\& TV (44.6\%) followed by newspapers \& magazines (41.6\%) and relatives and friends (41.4\%). Health care workers had the least role in this regard (9.5\%). Data have been presented in Table 1.

Mean $( \pm S D)$ score of participants' knowledge was $11.69 \pm 3.76$ (score range $=0-19$ ). Half of the participants gave correct answers to at most $54.5 \%$ of questions. As it is seen in Table 2, more than half of the studied women, mistook osteoporosis with arthrosis and also a high percent of them had no knowledge about the diagnosis of this disease. Almost half of the participants have knowledge about the time of reaching maximum bone strength. Awareness of participants toward risk factors of osteoporosis was different in a way that their awareness of female gender, early menopause and cigarette smoking as risk factors of osteoporosis was good, while they did not have enough awareness toward the role of genetics and advancing age and had poor awareness toward the role of corticosteroid and slimming. In relation to osteoporosis prevention, the highest rate of awareness was related to the effect of sunlight, exercise and cheese consumption, while they had moderate awareness toward the role of dried fig and the rate of milk consumption in menopause. Participants did not have sufficient awareness of the role of yoghurt and spinach. Although less than half of the participants knew shortening of height in old ages as a symptom of osteoporosis, in relation to susceptibility of osteoporosis patients to hip fracture had good awareness.

Awareness score showed no significant difference between the age groups of below and over 40 years and also between married and single subjects ( $p>0.05)$, but it showed significant difference based on the educational level; that is, mean awareness score of subjects with bachelor degree or higher was significantly higher than those with associate diploma degree or lower $(p<0.001)$.
Table 1. Sociodemographic characteristics of participants

\begin{tabular}{|c|c|}
\hline Variables & \\
\hline \multicolumn{2}{|l|}{ Age, years } \\
\hline Mean $\pm S D$ & $35.50 \pm 8.27$ \\
\hline Min.- Max. & $20-60$ \\
\hline \multicolumn{2}{|l|}{ Marital status, no. (\%) } \\
\hline Single & $86(21.7)$ \\
\hline Married & $302(76.3)$ \\
\hline No response & $8(2.0)$ \\
\hline Educational Level, no. (\%) & $(n=394)$ \\
\hline High school Diploma \& Below & $74(18.8)$ \\
\hline Associate Diploma & $64(16.2)$ \\
\hline Bachelor & $203(51.5)$ \\
\hline MS \& above & $53(13.5)$ \\
\hline Children Number, no. (\%) & $(n=229)$ \\
\hline 1 & $92(40.2)$ \\
\hline 2 & $90(39.3)$ \\
\hline 3 & $35(15.3)$ \\
\hline$\geq 4$ & $12(5.2)$ \\
\hline Menopause status, no. (\%) & $(n=396)$ \\
\hline Yes & $45(11.4)$ \\
\hline No & $351(88.6)$ \\
\hline Smoking, no. (\%) & $(n=389)$ \\
\hline Yes & $3(0.8)$ \\
\hline No & $386(99.2)$ \\
\hline Information about osteoporosis, no. (\%) & $(n=390)$ \\
\hline Yes & 377 (96.7) \\
\hline No & $13(3.3)$ \\
\hline Source of information, no. (\%) & $(n=377)$ \\
\hline Friends and Relatives & $156(41.4)$ \\
\hline Health Worker & $36(9.5)$ \\
\hline Physician & $100(26.5)$ \\
\hline News paper / Magazines & $157(41.6)$ \\
\hline Radio / TV & $168(44.6)$ \\
\hline Other & $58(15.4)$ \\
\hline
\end{tabular}

\section{Discussion}

Mean awareness score of studied subjects was 11.68 which is not good. Since our subjects were female employees, this low rate of awareness deserves more attention. Other studies that have been performed on different job groups in Iran have reported similar results. In Naeimi et al study, the awareness of physiotherapists toward osteoporosis was moderate [13]. Azizzadeh Foroozi et al, too, have reported low rate of awareness toward osteoporosis among teachers of Rafsanjan (Iran) [14]. In Jalili et al study, the awareness score of studied women had been $44.3 \%$ [12]. In whole, it seems that the rate of awareness toward osteoporosis is not good among special groups of society that are expected to have good awareness. Of course, this problem is not limited to Iran; for example, Terrio et al have studied the awareness of three age groups toward osteoporosis and reported low rate of awareness in all groups [4]. Chen et al in their study in Taiwan have reported the score of 34.16 out of 50 for the awareness of public health nurses [15]. In Zhang et al study in Singapore, mean awareness score of nurses toward osteoporosis was 14.5 from 20 [16]. In a study in Saudi Arabia by Barzanji et al, mean awareness score of Riyadh citizens was 13.6 out of 24 [17]. 
Table 2. Responses on questions about osteoporosis

\begin{tabular}{|c|c|c|c|}
\hline \multirow{2}{*}{ Questions } & \multicolumn{3}{|c|}{ no (\%) } \\
\hline & True & False & Unknown \\
\hline The probability of osteoporosis is equal in men and women. (F) & $321(80.7)$ & $17(4.3)$ & $60(15.1)$ \\
\hline Vit. B12 prevents osteoporosis. (F) & $64(16.1)$ & $143(35.9)$ & $191(48.0)$ \\
\hline Consumption of cortisone for more than one week, leads to osteoporosis. (T) & $39(9.8)$ & $261(65.6)$ & $98(24.6)$ \\
\hline Genetic factor have no relationship with osteoporosis. (F) & $163(41.0)$ & $114(28.6)$ & $121(30.4)$ \\
\hline Thin women get osteoporosis more than others. $(\mathrm{T})$ & $52(13.1)$ & $215(54.0)$ & $131(32.9)$ \\
\hline Exercise is not effective in prevention of osteoporosis. (F) & $321(80.7)$ & $36(9.0)$ & $41(10.3)$ \\
\hline Dried fig is a rich source of calcium. (T) & $228(57.3)$ & $16(4.0)$ & $154(38.7)$ \\
\hline Cheese is an important food in preventing osteoporosis. (T) & $288(72.4)$ & $38(9.5)$ & $72(18.1)$ \\
\hline Another name of osteoporosis is arthrosis. (F) & $178(44.7)$ & $126(31.7)$ & $94(23.6$ \\
\hline Smoking cigarette increases the risk of osteoporosis. (T) & $277(69.6)$ & $25(6.3)$ & $96(24.1)$ \\
\hline Spinach is a rich source of calcium. (T) & $118(29.6)$ & $191(48)$ & $89(22.4)$ \\
\hline Sun light reduces the risk of getting osteoporosis. (T) & $331(83.2)$ & $22(5.5)$ & $45(11.3)$ \\
\hline Women with osteoporosis should not be physically active. (F) & $239(60.1)$ & $79(19.8)$ & $80(20.1)$ \\
\hline The blood test should be done for osteoporosis diagnosis. (F) & $163(41.0)$ & $100(25.1)$ & $135(23.9)$ \\
\hline The skeleton riches its maximum strength at 20 years of age. (T) & $203(51.0)$ & $41(10.3)$ & $154(38.7)$ \\
\hline Women with early menopause (before 45 -year-olds) are more likely to get osteoporosis. (T) & $296(74.4)$ & $12(3.0)$ & $90(22.6)$ \\
\hline Risk of getting osteoporosis is more likely after the age of $65 .(T)$ & $159(39.9)$ & $106(26.6)$ & $133(33.4)$ \\
\hline One of the signs of osteoporosis disease is the shortening of height after the age of $65 .(T)$ & $167(42.0)$ & $166(41.7)$ & $65(16.3)$ \\
\hline Milk and yoghurt contain the same amount of calcium. (T) & $158(39.7)$ & $147(36.9)$ & $93(23.4)$ \\
\hline Osteoporosis related fractures also may occur by falling down on the carpet. (T) & $351(88.2)$ & $19(4.8)$ & $28(7.0)$ \\
\hline For supplying calcium needs during menopause, it is necessary to drink 5 cups of milk in a day. (T) & $203(51.0)$ & $41(10.3)$ & $154(38.7)$ \\
\hline There is no way to prevent osteoporosis. (F) & $309(77.6)$ & $35(8.8)$ & $54(13.6)$ \\
\hline
\end{tabular}

$\mathrm{F}$, false; $\mathrm{T}$, true.

According to the obtained results, significant part of our subjects had no adequate awareness of general aspects of osteoporosis in a way that half of them mistook osteoporosis with arthrosis and a great number had no information about its diagnosis. From all, $96 \%$ asserted that they had previously got some information about osteoporosis and their sources of information were mass media such as radio/TV, newspapers, magazines, relatives and friends, while physicians and health care workers had the least role in this relation. Since mass media's education might not be based on the real needs and information level of community, this situation is not unexpected. In Chen et al study, the awareness of nurses toward symptoms and also the diagnosis and treatment of osteoporosis was less than other aspects [15]. In Barzanji et al study, the most important source of information was TV (58.6\%) followed by relatives and friends $(30.0 \%)$, while health workers $(15.4 \%)$ had no considerable role in providing information about osteoporosis [17]. According to Wahba et al, the most important sources of information were respectively participants' mothers, relatives and friends (38.4\%), TV (30\%), while physicians (10.0\%) had a little role [18].

In the present study compared to Jalili et al study, awareness of participants toward the role of female gender, early menopause, cigarette smoking, genetics and advancing age in occurrence of osteoporosis was better, but our participants had less information about the role of corticosteroids and slimming [12]. In regard to the risk factors of osteoporosis, as compared to Zhang et al study, our participants' awareness of the role of female gender was almost similar, of early menopause and cigarette smoking was better but of slimming was less [16]. Alexandraki et al has reported low rate of awareness toward cigarette smoking, advancing age and corticosteroid consumption as risk factors of osteoporosis [19].

In relation to awareness of preventing factors of osteoporosis, our participants' awareness of the role of exposing to sunlight, exercise and cheese consumption was relatively good and almost half of them knew about the rate of milk consumption during menopause in order to supply the required calcium. In Azizzadeh Foroozy et al. study, participants had very good awareness of the role of exposing to sunlight and dairy products in osteoporosis prevention (more than 95\% correct answers to both items) [15]. In another study in Singapore, more than half of nurses had awareness of the beneficial role of exercise in bone health and more than $70 \%$ had information about the amount of daily milk that should be consumed by menopause women [16]. Taiwanese nurses, too, had gained acceptable score in regard to osteoporosis prevention [15].

The awareness of our participants showed no significant difference based on their age and this finding is similar to what has been reported in a study in Saudi Arabia [17]. In the present study, awareness showed significant difference based on educational level in a way that women with university degrees showed higher rate of awareness. Another study in Iran has also reported higher rate of awareness of osteoporosis among women with higher educational levels [20]. The results of other studies in America [4], Taiwan [15] and Saudi Arabia [17] have also shown that those with higher educational levels have higher awareness of osteoporosis.

A review of the results of several studies in different parts of the world shows that unfortunately in many cases, awareness of osteoporosis is not good, while this disease in addition to having a high prevalence rate, especially in women, has several complications that eventually affect both the patient and the patient's relatives.

\section{Conclusion}

One of the significant findings was low rate of awareness of osteoporosis among our subjects and since they were employees with better social statues compared to other women, it was expected that they show acceptable rate of awareness of different health issues. 
Another point worthy of attention is poor role of health workers and physicians in relation to increasing our participants' awareness of osteoporosis, while it was expected that this group play a more considerable role in society's education. Accordingly, in the first step, it is necessary to evaluate the needs of each special group in the community, then prepare educational packages based on the needs and finally present them to the target groups via mass media. Simultaneously, Retraining programs should be presented for health workers and physicians. On the other hand, implementation of educational programs for different groups of community, especially women, by health care system is necessary. It is obvious that face to face educational programs are more efficient compared to mass media education.

\section{Study limitation}

As a study limitation, the present study was limited to female employees of just a number of offices in Kerman/ Iran. Moreover, lack of a control group consisting of jobless women or women working in non-official sectors in order to compare the results was another limitation of the present study.

Conflicting Interest: none declared.

\section{References}

1. Masi L. Epidemiology of osteoporosis. Clin Cases Miner Bone Metab 2008; 5(1): 11-13. (PMCID: PMC2781190) (PMID: 22460840)

2. Rachner TD, Khosla S, Hofbauer LC. Osteoporosis: now and the future. Lancet 2011; 377(9773): 1276-1287. (PMID: 21450337) (PMCID: PMC3555696) (doi: 10.1016/S0140-6736(10)62349-5)

3. Werner P. Knowledge about osteoporosis: assessment, correlates and outcomes. Osteoporos Int 2005; 16(2): 115-127. (PMID: 15517187) (doi: 10.1007/s00198-004-1750-y)

4. Terrio K, Auld G.W. Osteoporosis knowledge, calcium intake, and weight-bearing physical activity in three age groups of women. $\mathrm{J} J$ Community Health 2002; 27(5): 307-320. (PMID: 12238730)

5. Berarducci A. Senior nursing students' knowledge of osteoporosis. Orthop Nurs 2004; 23(2): 121-127. (PMID: 15103798)

6. Hernandez-Rauda R, Martinez-Garcia S. Osteoporosis-related life habits and knowledge about osteoporosis among women in El Salvador: a cross-sectional study. BMC Musculoskelet Disord 2004; 5: 29. (PMID: 15329150) (PMCID: PMC517502)

7. Kilbanski A, Adams-Campbell L, Bassford T, Blair SN, Boden SD, Dickersin $\mathrm{K}$, et al. Osteoporosis prevention, diagnosis, and therapy. JAMA 2001; 285(6): 785-795. (doi: 10.1001/jama.285.6.785) (PMID: 11176917)

8. Keramat A, Patwardhan B, Larijani B, Chopra A, Mithal A, Chakravarty $D$, et al. The assessment of osteoporosis risk factors in Iranian women compared with Indian women. BMC Musculoskelet Disord 2008; 9: 28. (doi: 10.1186/1471-2474-9-28) (PMID: 18304358) (PMCID: PMC2289820)

9. Ungan M, Tümer M. Women's knowledge of osteoporosis. Fam Pract 2001; 18(2): 199-203. (doi: 10.1093/fampra/18.2.199) (PMID: 11264272)

10. Vered I, Werner P, Shemy G, Stone O. Nurses' knowledge and perceptions about osteoporosis: a questionnaire survey. Int J Nurs Stud 2008; 45(6): 847-854. (PMID: 17362958) (doi: 10.1016/j.ijnurstu.2007.01.011)

11. Ziccardi SL, Sedlak CA, Doheny MO. Knowledge and health beliefs of osteoporosis in college nursing students. Orthop Nurs 2004; 23(2): 128-133. (PMID: 15103799)

12. Jalili Z, Nakhaee N, Askari R, Sharifi V. Knowledge, attitude and preventive practice of women concerning osteoporosis. J Community
Health 2013; 38(6): 1098-1105. (doi: 10.1007/s10900-013-9719-4) (PMID: 23780302)

13. Naeimi S, Sedaghat L. Physiotherapist performance and attitude towards osteoporosis in Tehran, 1999-2000. Pejouhesh 2003; 27(1) 57-62.

14. Azizzadeh Forozi M, Haghdoost AA, Saidzadeh Z, Mohamadalizadh S. Study of knowledge and attitude of Rafsanjanian female teachers toward prevention of osteoporosis. Journal of Birjand University of Medical Sciences 2009, 16(1): 71-77.

15. Chen IJ, YU S, Wang TF, Cheng SP, Huang LH. Knowledge about osteoporosis and its related factors among public health nurses in Taiwan. Osteoporos Int 2005; 16(12): 2142-2148. (PMID: 16133637) (doi: 10.1007/s00198-005-2015-0)

16. Zhang RF, Chandran M. Knowledge of osteoporosis and its related risk factors among nursing professionals. Singapore Med J 2011; 52(3): 158-162. (PMID: 21451923)

17. Barzanji AT, Alamri FA, Mohamed AG. Osteoporosis: a study of knowledge, attitude and practice among adults in Riyadh, Saud Arabia. J Community Health 2013; 38(6): 1098-1105. (doi 10.1007/s10900-013-9719-4) (PMID: 23780302)

18. Wahba SA, El-Shaheed AA, Tawheed MS, Mekkawy AA, Arrafa AM Osteoporosis knowledge, beliefs, and behaviors among Egyption female students. JASMR 2010; 5(2): 173-180.

19. Alexandraki KI, Syriou V, Ziakas PD, Apostolpoulos NV, Alexandrakis AI, Piperi $\mathrm{C}$, et al. The knowledge of osteoporosis risk factors in a Greek female population. Maturitas 2008; 59(1): 38-45. (PMID: 18079073) (doi: 10.1016/j.maturitas.2007.10.008)

20. Etemadifar MR, Nourian SM, Fereidan-Esfahani M, Shemshaki HR, Nourbakhsh M, Zarezadeh A. Relationship of knowledge about osteoporosis with education level and life habits. World J Orthop 2013; 4(3): 139-143. (doi: 10.5312/wjo.v4.i3.139) (PMCID: PMC3717248) (PMID: 23878783)

\section{Authors:}

Mansoureh Safizadeh - MD, MPH, Research Center for Social Determinants of Health, Institute for Futures Studies in Health, Kerman University of Medical Sciences, Kerman, Iran.

Elahe Aminizadeh - Medical Student, Research Committee, Kerman University of Medical Sciences, Kerman, Iran.

Hossein Safizadeh - Associate Professor of Community Medicne, Research Center for Social Determinants of Health, Institute for Futures Studies in Health, Kerman University of Medical Sciences, Kerman, Iran. 